\title{
Feature PSI in Patients with Pathology of the Maximum-Face Region
}

\author{
Dmitrii A. Stepanov, Evgenii A. Stepanov, Natalia N. Mitrofanova, Viktoriia S. Leibenko, Viktoriia V. \\ Mel'nikova
}

\begin{abstract}
Currently, there is an acute problem of nosocomial purulent-septic infection (PSI), aggravating the course of the underlying disease, increasing the length of stay in the surgical hospital.An analysis of 104 case histories of patients of the Department of Oral and Maxillofacial Surgery for 2016 was performed, among them $55.77 \%$ of men and $44.23 \%$ of women. Studies included bacteriological analysis of isolates and determination of the antibiotic sensitivity spectrum of the selected cultures.PSI are the most common complications in patients with pathologies of the maxillofacial region. The etiological agents of PSI in patients with pathologies of the maxillofacial region are mainly gram-positive microorganisms represented by genera. Staphylococcus and Streptococcus. For antibacterial therapy in the department of oral surgery for patients, it is rational to use preparations of the group cephalosporins, aminoglycosides and tetracyclines.
\end{abstract}

Key words: purulent-septic infection, maxillofacial surgery department, etiological structure, antibiotic therapy.

\section{I.INTRODUCTION}

Currently, there is an acute problem of nosocomial purulent-septic infection (PSI), aggravating the course of the underlying disease, increasing the length of hospital stay. Inflammatory processes in dental patients arising in the departments of maxillofacial surgery are of great interest to the surgeon, as there is a progressive increase in the number of patients with inflammatory processes in the maxillofacial region, a prolonged and relapsing course of PSI with the development of complications, which play a major role in disability and an increased risk of death, hospital strains have high virulence, antibiotic resistance, resistance to disinfectants, a wide spectrum pathogenicity factors, PSI in surgical dentistry, unlike other departments of the surgical profile, at present being poorly studied, there are many questions related to general patterns and characteristics of the course, infection, development of a set of measures aimed at preventing the occurrence of PSI $[1 ; 2 ; 3 ; 4 ; 5]$.The available works on hospital infection today contain numerous microbiological studies,

Revised Manuscript Received on February 08, 2020.

* Correspondence Author

Dmitrii A. Stepanov*, student, Medical Institute, Penza State University, Penza, Russia. E-mail: stomsd@yandex.ru

Evgenii A. Stepanov, graduate student, Medical Institute, Penza State University, Penza, Russia. E-mail: stepanow.evgenyi95@mail.ru

Natalia N. Mitrofanova,senior lecturer, Medical Institute, Penza State University, Penza, Russia. E-mail: meidpgumi@yandex.ru

ViktoriiaS. Leibenko student, Medical Institute, Penza State University, Penza, Russia. E-mail: leibenkov@icloud.com

Viktoriia V. Mel'nikovaordinator, Medical Institute, Penza State University, Penza, Russia. E-mail: viktopiamelnikova-98@mail.ru

(C) The Authors. Published by Blue Eyes Intelligence Engineering and Sciences Publication (BEIESP). This is an open access article under the CC BY-NC-ND license (http://creativecommons.org/licenses/by-nc-nd/4.0/) during which it was determined that most of the inflammatory diseases of the maxillofacial region are caused by the action of microflora that inhabit the main biotopes of the human body, microorganisms growing in the oral cavity are of particular importance $[6 ; 7 ; 8]$.

The inflammatory process is determined by endogenous or exogenous infection. The source of exogenous microbial contamination can be both the patient himself and the medical staff $[9,10]$. The main role in the occurrence of PSI in the Department of Oral and Maxillofacial Surgery belongs to endogenous purulent-septic infections, which account for $80.8 \%$ of all nosocomial PSI [11].

Odontogenic and non-odontogenic inflammatory diseases of the maxillofacial region are distinguished. Odontogenic foci of inflammation are formed as a result of aggressive effects from aerobic and facultative anaerobic microflora of the oral cavity - staphylococci, streptococci, gram-positive and gram-negative rods, etc. The cause of PSI can be both individual types of microorganisms and their associations. Inflammations of non-odontogenic origin are characterized by a predominance of streptococci, staphylococci, rarely bacilli and obligate anaerobes. When cultivating the studied material, monocultures are often distinguished [12; 13; 14; $15 ; 16]$.

Recent scientific papers contain data on factors that increase the risk of nosocomial infections. Two groups are distinguished among them: 1) factors reflecting the condition of the patient (age, concomitant diseases, immunity (according to the observations of practicing surgeons, the immunity of many modern patients is low), etc.); 2) factors caused by the provision of medical care (untimely and irrational use of antibiotics for prevention or treatment, etc.) $[17 ; 18 ; 19]$.

Despite the improvement of the treatment and diagnostic process, the development of new methods aimed at preventing the occurrence and elimination of a purulent focus, compliance with all aseptic rules, the number of inflammatory complications does not tend to decrease $[1 ; 6$; $12 ; 17 ; 18 ; 19]$.

In this regard, the goal of our work was to analyze the nosocomial PSI arising in the conditions of the Department of Oral and Maxillofacial Surgery of a multidisciplinary hospital.

\section{II.METHODOLOGY}

This research work consisted of several stages. At the first stage, a review of Russian literature was carried out, in which there was information about PSI in patients with diseases of the maxillofacial region.

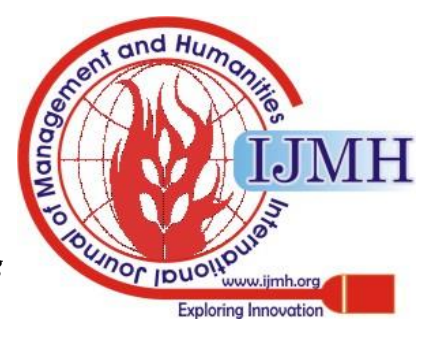


The second stage consisted of collecting clinical and anamnestic data from 104 patients of the Department of Maxillofacial Surgery of a multidisciplinary hospital, collecting material for examination (smears from wounds, the oral cavity, nasal passage, ear, wound discharge), conducting a microbiological study of isolates (establishing representatives of microflora with various nosological forms of diseases of the maxillofacial region, determining the sensitivity of selected cultures to chemotherapeutic drugs according to clinical recommendations by disc-diffusion antibiotic sensitivity test). At the third stage, statistical processing of the obtained data was carried out using the Microsoft Office software package, during which the dominant microflora was established for various nosological forms of diseases of the maxillofacial region and which chemotherapeutic agents should be rationally used to treat these diseases taking into account the etiological agent.

\section{III.RESULTS}

As a result of a retrospective analysis of case histories of 104 patients of the Department of Oral and Maxillofacial Surgery, it was revealed that most of the victims belong to the male population - 58 (55.77\%), the remaining 46 (44.23\%) - women (Fig. 1).
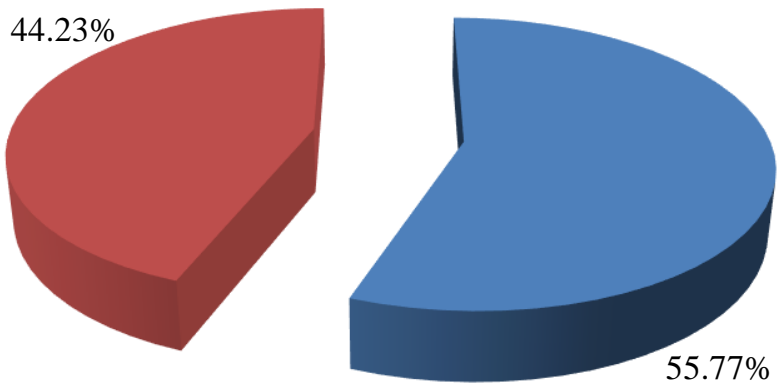

- Men $\quad$ Women

Fig. 1.Features of the sexual structure of patients with GSI of the Department of Oral and Maxillofacial Surgery multidisciplinary hospital.

Most men of the studied population are in the age tranche from 25 to 44 years old, in women from 15 to 30 years old (Fig. 2). The average age of patients with PSI of the Department of Oral and Maxillofacial Surgery was $~ 39$ (39.66) years.

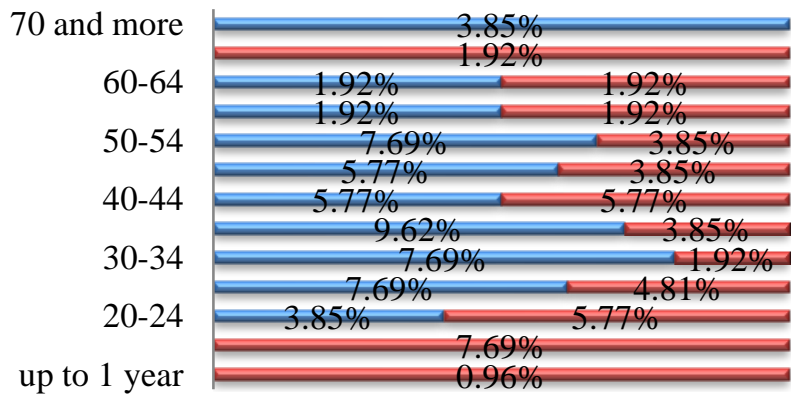

$\square$ Men $\square$ Women
Fig. 2. Features of the age structure of patients in the Department of Oral and Maxillofacial Surgery multidisciplinary hospital.

Of the 58 men included in the study, 18 (31.03\%) belong to the category of working people and 40 (68.97\%) are temporarily unemployed (Fig. 4). Among them: 2 (3.45\%) of a group II disabled person (38 years old), 8 pensioners (13.79\%).

Among patients in the Department of Oral and Maxillofacial Surgery with PSI, 60 (57.69\%) people did not have any concomitant diseases, and 44 (42.31\%) had pathologies from various systems and organs, the most common are disorders in the work of cardio vascular system: in 18 (17.31\%) patients diagnosed with hypertension of various severity, in 4 (3.85\%) patients coronary heart disease, atherosclerotic cardiosclerosis.

The presence of immunopathological processes in the form of allergic reactions to penicillin-type antibiotics is present in 2 (1.92\%) of the studied population.

Burdened heredity was established in $1(0.96 \%)$ case: violation of the autosomal recessive type of inheritance Q35.5 - cleft hard and soft palate. Also, the presence of cerebral ischemia, congenital dislocation of the hip (hip dysplasia) was noted in this patient.

All subjects are characterized by living in satisfactory conditions.

The following complications of the maxillofacial region were found in patients of the Department of Oral and Maxillofacial Surgery - inflammatory diseases of the jaw, root cyst, phlegmon and abscess of the oral cavity, abnormalities in the position of the teeth, benign neoplasm of the adipose tissue of the skin and subcutaneous tissue of the head, face and neck, acute purulent otitis media, acute maxillary sinusitis, chronic maxillary sinusitis, fistulas, skin abscesses, boils and carbuncles, jaw fractures (Fig. 3):

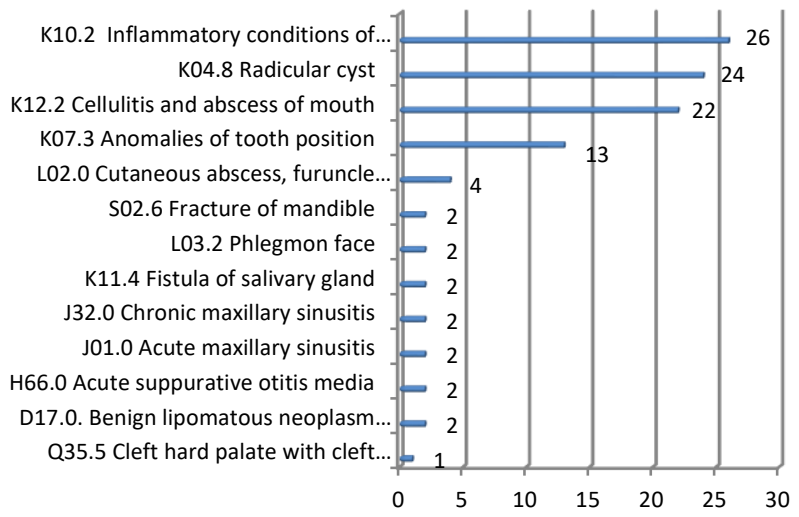

Fig. 3.Features of PSI in patients of the Department of Oral and Maxillofacial Surgery.

\section{IV.DISCUSSION}

It was established that the isolates isolated from the hospital environment are mainly represented by grampositive microorganisms - $98.08 \%$, the proportion of gramnegative cultures was $1.92 \%$ (Fig. 4).

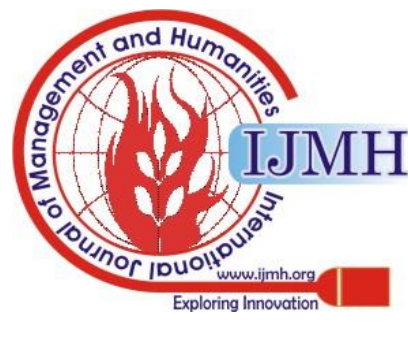


It was found that among the gram-positive etiological agents of PSI in patients of the Department of Oral and Maxillofacial Surgery of a multidisciplinary hospital, representatives of the genera Streptococcus prevail - 39.42\% and Staphylococcus - 28.85\%.

Moreover, Streptococcus viridans confidently dominates among Streptococcus - 38.46\%, Staphylococcus epidermidis - 23.08\% among staphylococci.

The presence of microbial associations was detected - in 1 case there was simultaneous abundant growth of Streptococcus viridans and meager growth of fungi of the genus Candida, and in 1 case, moderate growth of Staphylococcus aureus and abundant growth of Enterococcus faecalis was simultaneously observed.

After antibiotic therapy, in two cases repeated bacteriological studies were performed, in which they received:

- lack of growth of microorganisms

The first study was conducted on 02.24.16 Staphylococcus epidermidis was isolated - growth from the filling medium. 02.24.16, the patient was prescribed cefotaxime and ciprofloxacin. A second study was done on 02.25.16.

- change of microflora of Staphylococcus hominis to Staphylococcus epidermidis

On January 16, 2016, Staphylococcus hominis was identified during microbiological examination. After a course of antibacterial therapy with pefloxacin, on $01 / 26 / 16$, a second study was conducted, in which moderate growth of Staphylococcus epidermidis was observed.

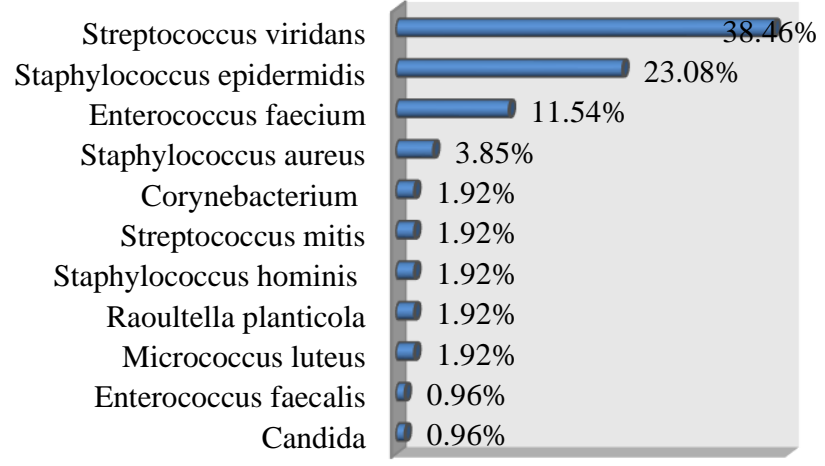

Fig. 4.The etiological structure of etiological agents of PSI in patients of the Department of Oral and

Maxillofacial Surgery multidisciplinary hospital.

As a result of the studies, a correlation dependence was found in the ratio of the nosological forms of the purulent pathological process of the maxillofacial region and the main etiological agents that initiate the infectious process. For inflammatory diseases of the jaw, fistula and sinusitis, the main etiological agent is Staphylococcus epidermidis, for phlegmon and abscesses and boils, in equal shares of Staphylococcus epidermidis and Streptococcus viridans, and for sinusitis and cysts, the main pathogen is Streptococcusvidans (Table 1).

According to our data, most strains of Streptococcus viridans, obtained from the clinical material of the Department of Oral and Maxillofacial Surgery in a multidisciplinary hospital, are sensitive to doxycycline and chloramphenicol. The isolated strains exhibit significantly lower therapeutic activity to linezolid and clarithromycin. The use of levofloxacin is ineffective.

For Staphylococcus epidermidis isolated from patients of the Department of Oral and Maxillofacial Surgery of a multidisciplinary hospital, the presence of strains resistant to benzylpenicillin and ampicillin is characteristic. Most isolates are sensitive to amikacin and fusidine, slightly sensitive to tetracycline and chloramphenicol.

For antimicrobial therapy of maxillofacial PSI, a wide range of drugs was used, among which the antibiotics of the cephalosporins and fluoroquinolones group - ceftriaxone, ciprofloxacin and pefloxacin predominate. Most patients who received antibiotic therapy were discharged in satisfactory condition.

Table 1 - Analysis of the structure of etiological agents depending on nosological forms of purulent-septic complications

\begin{tabular}{|c|c|}
\hline Nosologicalform & Microflora \\
\hline $\begin{array}{c}\text { J01.0 } \\
\text { Acutemaxillarysinusitis }\end{array}$ & Staphylococcusepidermidis (100\%) \\
\hline $\begin{array}{c}\text { J32.0 } \\
\text { Chronicmaxillarysinusitis }\end{array}$ & Streptococcusviridans (100\%) \\
\hline K04.8 Radicularcyst & $\begin{array}{l}\text { - Enterococcusfaecium (33,3\%); } \\
\text { - Streptococcus viridans (58,3 \%) } \\
\text { in } 1 \text { case sparse growth of fungi } \\
\text { of the genus Candida); } \\
\text { - nogrowth }(8,4 \%)\end{array}$ \\
\hline $\begin{array}{c}\text { K07.3 Anomalies of tooth } \\
\text { position }\end{array}$ & $\begin{array}{l}\text { - Enterococcus faecium (15,4\%); } \\
\text { - Staphylococcus aureus (15,4\%) } \\
\text { (and abundant growth of } \\
\text { Enterococcus faecalis in } 1 \text { case); } \\
\text { - Streptococcusviridans (53,8 \%); } \\
\text { - nogrowth(15,4\%) } \\
\end{array}$ \\
\hline $\begin{array}{l}\text { K10.2 Inflammatory } \\
\text { conditions of jaws }\end{array}$ & $\begin{array}{l}\text { - Staphylococcus epidermidis } \\
\text { ( } 46,1 \%) ; \\
\text { - Enterococcus faecium }(7,7 \%) ; \\
\text { - Streptococcus viridans }(30,8 \%) ; \\
\text { - } \text { Corynebacterium }(7,7 \%) ; \\
\text { - nogrowth }(7,7 \%) \\
\end{array}$ \\
\hline $\begin{array}{c}\text { K11.4 Fistula of salivary } \\
\text { gland }\end{array}$ & Staphylococcusepidermidis (100\%) \\
\hline $\begin{array}{l}\text { K12.2 Cellulitis and } \\
\text { abscess of mouth }\end{array}$ & $\begin{array}{l}\text { - } \text { Micrococcus luteus }(9,1 \%) ; \\
\text { - Staphylococcus epidermidis } \\
(27,2 \%)(1 \text { case of microflora } \\
\text { change: Staphylococcus hominis - } \\
\text { Staphylococcus epidermidis); } \\
\text { - Streptococcus viridans }(27,2 \%) ; \\
\text { - Streptococcus mitis }(9,1 \%) ; \\
\text { - Raoultellaplanticola }(9,1 \%) ; \\
\text { - nogrowth }(18,2 \%) \\
\end{array}$ \\
\hline $\begin{array}{l}\text { L02.0 Cutaneous abscess, } \\
\text { furuncle and carbuncle of } \\
\text { face }\end{array}$ & $\begin{array}{l}\text { - Staphylococcus aureus (50\%); } \\
\text { - Staphylococcus epidermidis } \\
(50 \%)\end{array}$ \\
\hline $\begin{array}{c}\text { Q35.5 Cleft hard palate } \\
\text { with cleft soft palate }\end{array}$ & treptococcusviridans (100\%) \\
\hline $\begin{array}{c}\text { S02.6 } \\
\text { Fractureofmandible }\end{array}$ & treptococcusviridans (100\%) \\
\hline
\end{tabular}

Published By:

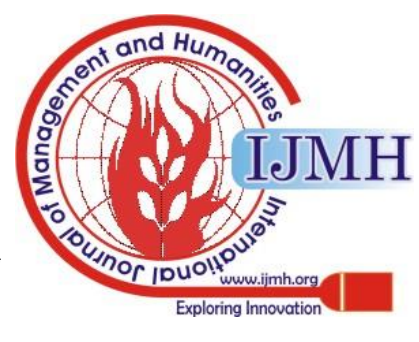




\section{V.CONCLUSIONS}

According to the analysis of clinical and medical history information and laboratory and clinical research data, the etiological agents of PSI in patients of the maxillofacial surgery department of a multidisciplinary hospital are most often gram-positive microorganisms represented by Streptococcus viridans and Staphylococcus epidermidis. The results of determining the sensitivity of selected cultures to chemotherapeutic drugs by the disc-diffusion antibiotic sensitivity test showed that for the etiotropic treatment of purulent-inflammatory diseases of the maxillofacial region in patients undergoing treatment in the Department of Maxillofacial Surgery of a multidisciplinary hospital, it is rational to use antibacterial drugs of cephalosporin groups, aminoglycosides and tetracyclines. The use of broadspectrum chemotherapeutic agents is justified only as starting therapy and can be prescribed only for the period until the results of a bacteriological study are obtained, after which it should be adjusted according to the results of antibiotic resistance tests of the leading representatives of microflora.

\section{REFERENCES}

1. Goncharenko S.A. Septicemia prospects of purulent nosocomial infections in oral surgery and dentistry / S.A. Goncharenko // Materials of the scientific and practical conference with international participation April 1-2, 2004 - Kharkiv: Kharkiv National University named after VN Goncharenko. Karazin, Publishing Center, 2004, pp.73.

2. Kabanova S.A. Features of the formation of resistance of microorganisms in the department of oral surgery / SA Kabanova [and others] // Vestnik Vitebsk State Medical University. 2005, vol. 4, no. 1, pp. 109-114.

3. Mamedova N.M. Estimation of the etiological structure of purulentseptic infectious complications in dentistry / N.M. Mamedova // Fundamental research. 2015, no. 1-8, pp. 1621-1624.

4. Omarova S.M. Monitoring of antibiotic-resistant staphylococci, pathogens of intrahospital infection of patients in the department of oral surgery / S.M. Omarova [and others] // International Scientific and Research Journal. 2017, no. 02 (56), part 2, pp. 30-33.

5. Robustova T.G. Surgical dentistry and oral surgery: National leadership / T.G. Robustova [and others]. Moscow: GEOTAR-Media, 2010, $928 \mathrm{p}$.

6. Zueva L.P. The problem of nosocomial infections in dentistry: Newsletter / L.P. Zuev [and others]. St. Petersburg, 2004, 25 p.

7. Kuldasheva V.B. The use of modern means in the rehabilitation of patients with inflammatory processes of the maxillofacial area: dis. to the soisk. akadem. step. Master's degree: 5A 510401 / KuldashevaVaziraBakhodurovna; Tashkent State Dental Institute. Tashkent, 2015, 77 p.

8. Shargorodsky A.G. Inflammatory diseases of the tissues of the maxillofacial region and neck / A.G. Shargorodsky. Moscow: GOU VUNMTS MH RF, 2001, 271 p.

9. Kabanova S.A. Epidemiological features of hospital surgical infection of maxillofacial area / S.A. Kabanova [and others] // Vestnik of Vitebsk State Medical University. 2003, vol. 2, no. 1, pp. 35-40.

10. Solomay T.V. Purulent-septic infections in dentistry / T.V. Solomay, A. N. Cairo // Sanitary doctor. 2011, no. 9, pp. 8-13.

11. Molchanovskaya M.A. Epidemiological features of purulent complications in the provision of dental care: the author's abstract. dis. to the soisk. scientist. step. cms (14.00.30) / Molchanovskaya Maria Aleksandrovna; St. Petersburg State Medical Academy. I.I. Mechnikov. St. Petersburg, 2005, 24 p.

12. Dydykin V.F. Treatment of severe purulent infection of the maxillofacial region and neck / V.F. Dydykin, V.V. Kovshov // Siberian Medical Journal. 2006, vol. 66, no. 8, pp. 21-23.

13. Kabanova S.A. Features of the microbial spectrum and sensitivity to antibiotics of microorganisms isolated from patients and staff of the Department of Oral Surgery / S.A. Kabanova [and others] // Immunopathology, allergology, infectology. 2000, no. 2, pp. 107-111.

14. Kovaleva N.S. Antibacterial therapy of purulent-inflammatory diseases of the maxillofacial area: pharmacoepidemiological and clinical microbiological research / N.S. Kovaleva [and others] // Clinical microbiology and antimicrobial chemotherapy. 2011, no. 4, pp. $360-$ 368.

15. Strachunsky, L.S. Practical guidance on anti-infectious chemotherapy/ L.S. Strachunsky [and others]. - Smolensk: Interregional Association. on clinical microbiology and antimicrobial chemotherapy, 2007, 462 p.

16. Usmanova G.M. Epidemiological features of nosocomial infections in health facilities of various profiles and measures for their prevention in the Republic of Tajikistan: author's abstract. dis. to the soisk. scientist. step. Ph.D. (14.02.02) / UsmanovGulnoraMukimovna; Tajik State Medical University. Abualiibni Sino MH RT. Moscow, 2012, 43 p.

17. Afanasyev V.V. Surgical stomatology: textbook / B.B. Afanasyev [and others]. Moscow: GEOTAR-Media, 2016, 400 p.

18. Omarova SM Microbiological characteristics of the objects of the nosocomial environment of the surgical departments of the dental profile / SM Omarova [and others] // Medical almanac. 2016, no. 3 (43), pp. 166.

19. Timofeev A.A. Prevention of purulent-inflammatory complications in surgical dentistry and oral surgery / A.A. Timofeev // The stomatologist-practitioner. 2015, no. 4, pp. 34-38.

\section{AUTHORS PROFILE}

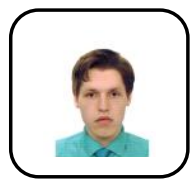

Dmitrii A. Stepanov, student, Medical Institute, Penza State University, Penza, Russia. The author has published scientific works in the field of medical technology, on purulent-inflammatory diseases of the maxillofacial region in patients of maxillofacial surgery.

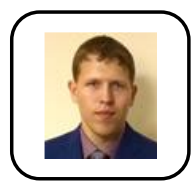

Evgenii A. Stepanov, graduate student, Medical Institute, Penza State University, Penza, Russia. The author has published scientific works on pathologies of periodontal tissues, purulent-inflammatory diseases of the maxillofacial region.

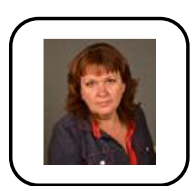

Natalia N. Mitrofanova, senior lecturer, Medical Institute, Penza State University, Penza, Russia. The author has published works on the study of nosocomial infections, microcenoses of the human body, and dysbiosis.



Viktoriia S. Leibenko,student, Medical Institute, Penza State University, Penza, Russia. The author has published works on maxillofacial surgery.

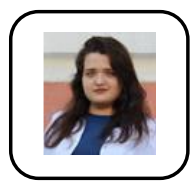

Viktoriia V. Mel'nikova,ordinator, Medical Institute, Penza State University, Penza, Russia. The author published a study on inflammatory diseases of the soft tissues of the maxillofacial region.

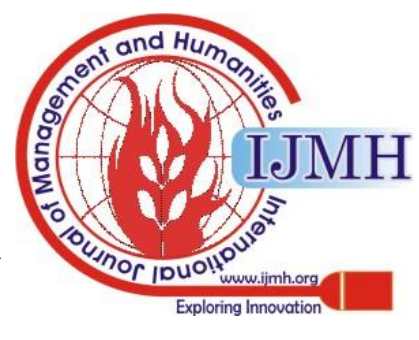

